\title{
Competence Development in Theory and Practice: Competence, Meta-Competence, Transfer Competence and Competence Development in Their Systematic Context
}

\author{
CHRISTOPH BACH \\ Comenius University in Bratislava, Slovak Republic \\ ch.bach-frankfurt@t-online.de \\ ROZÁLIÁ SULIKOVÁ \\ Comenius University in Bratislava, Slovak Republic \\ rozalia.sulikova@fm.uniba.sk
}

This work raises the question, why the contents of trainings in further education are often not applied in operational and everyday business. The authors do not want to leave it at that but rather focus on the transfer of what has been learned in a training and how trainings should be structured after all so that transfer can indeed take place. For this purpose, the term 'competence' is introduced at first, which should not be confused with 'knowledge.' Competences rather are 'applied knowledge.' Then the concept of meta-competence is introduced. Meta-competence means a competence of using competences which is of interest especially to leaders. Finally we look at transfer competence, which is the ability to apply acquired knowledge in practice. Classic trainings fail to make knowledge relevant for practice because only little or no transfer competence is activated. Therefore, towards the end of this work, we introduce a training measure, which systematically activates transfer competence and focuses on competences. For this reason, the correct name of this type of training should be 'competence development.'

Key words: competence, meta-competence, transfer competence, competence development https://doi.org/10.26493/1854-4231.14.289-304

\section{Introduction}

This paper aims to address a problem that many, if not all, face in adult education: After the training, the participants (especially in leadership seminars) have gained knowledge about behaviour in 
companies. They would now have to become better leaders. However, it is often stated in practice that this is not the case, or if so, only to a very limited extent.

From a conceptual perspective, especially with regard to competence development among managers, the above problem can be narrowed down to the following terms: competence, competence development and competence development programmes, meta-competence and transfer competence.

Against the background of these terms, it can be said that the failure of training is related to transfer competence (or its inactivation). Also of great importance in this context is the so-called 'inert knowledge,' that is, knowledge that exists in an abstract sense but is actually not applied in practice.

After these concepts will have been presented in context, the main focus of this paper will be on investigating the question of how failure of transfer can be counteracted in practice. It will turn out that volition, a term that goes back to Pelz, is of great importance.

Following this, transfer competence will be analysed again in more detail. In particular, it should be noted that, unlike many other competences, transfer competence cannot be developed in a conventional sense, rather, it must be aroused. The two concluding chapters then focus on activating transfer competence in trainings: First, the focus is on failure in traditional further education. Following this, a competence development programme will be presented which enables transfer competence to be activated.

\section{Competences}

At first it seems important that the paper approaches the concept of competence. Competences are not skills, knowledge or qualifications, but rather a higher-order ability, namely to act creatively and self-organised in unexpected and often chaotic situations (see Heyse, Erpenbeck, and Ortmann 2015, 13). However, competencybased action does not mean it is 'theory-free.' Competences form a kind of bridge or hinge between theory and practice. In a sense, they could be said to be manifestations of applied theory.

In the modern world of work, with its many challenges, of which globalisation is not the least important, competences seem to be enormously important. Although every employee of a company must have specific competences, it is clear that managers in particular have to acquire specific skills.

At this point, not all competences should be examined, but specific ones, namely the so-called leadership competences should be

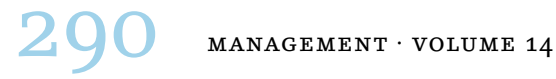


explained. In order to be able to approach this, a classification of competences frequently used in literature is presented first (Schäfer 2006, 17):

- Professional competences

- Methodological competence

- Social competence

- Self-competences

Professional competences are those that are necessary for coping with typical problems in the respective profession. For the most part, they are closely linked to one's expertise. Methodological competences go beyond these: they include the ability to solve problems or to acquire knowledge. Social competences are competences aimed at social interaction: communicative competences are to be mentioned here first but also conflict management competences should be mentioned in this connection. Self-competences could be understood as reflexive competences: The individual uses them to refer to him- or herself: values, general attitudes but also self-perception are to be mentioned in this context.

It is easy to see that within this categorisation all possible competences can be located so that they constitute each other: Professional competences constitute methodological competences and social competences establish self-competences. Furthermore, it is obvious that the first two competences are directly work-related, for example, the production of particular goods, while the last two relate to people and, ultimately, how to lead them. In this sense, these last two competences, social and self-competence, seem to be typical of leadership skills while the first two appear to be types of competences that should be typical of subordinates.

If, however, the actual competence is to act creatively and selforganised in chaotic situations it becomes clear that all four types of competence are needed: The person acting in this sense requires professional, methodical, social and ultimately also selfcompetences. In this sense, acting competently means using all competence resources available. Action competence can be understood as the competence of all competences insofar as it refers to the entire person in the working world. It is a leadership competence. If, on the one hand, action competence is based on professional competences at its core then, on the other hand, it should be stressed also that competent leaders always starts by using their own selfcompetences and thus lead and guide themselves. Based on these self-competences they can lead others because of their social com- 
petence. But in order to lead others, it requires methodological competence, which in turn leads to professional competence. Hence, the different types of competences are ultimately so intertwined that one can hardly speak of one type of competence being more important than the other.

\section{COMPETENCE DEVELOPMENT PROGRAMMES}

According to Erpenbeck and Sauer (2001, 294), competence development means 'a process of expanding, restructuring and updating a person's professional, methodical, social and personal options for action.' As a result, competence development cannot emerge from knowledge or skills taught in trainings, even though both are necessary prerequisites for successful competence development.

Classic trainings, however, provide exactly this: a certain knowledge or certain skills. The disadvantage of this type of training is that it is not always immediately obvious to the participants how, when and where the acquired knowledge has to be applied. Therefore, the central problem is the practical relevance, that is, putting into action what has been learned. In other words: no competences are developed in these types of trainings.

Instead of relying on classic training programmes, there has been an emphasis in recent years to focus on so-called competence development programmes. These differ from trainings in that practice is the main focus. Above all, these programmes are meant to actually apply what has been learned. It should be emphasised here that theory is by no means neglected, it is rather about the interplay of theory and practice, while classic training programmes have often relied only on theory.

In a first step, it can be stated that successful competence development programmes should try to help people implement the transfer of the acquired knowledge into practice. But this leads to the question of how to do this. So what distinguishes a competence development programme from a classic programme, where there is always the danger that skills are developed and knowledge is generated but that they might not be relevant for practice?

META-COMPETENCE

To answer this question, the concept of meta-competence must be addressed at first. Although the term is not particularly prominent in organisational, management and competence research, it is certainly not re-introduced at this point. It ultimately goes back to Burgoyne, who first used it in 1988. According to him, it is a special compe-

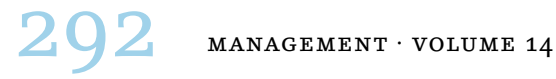


tence that allows to adapt or even develop skills in specific situations (Burgoyne 1988). In this respect, the above statement that all competences can be found in the four categories must be modified. Meta-competences - insofar as they are ultimately to be understood as a competence of using competences - cannot just be classified under the above mentioned.

The relationship of meta-competence to others is formally comparable to the relationship of competences to actions. In this sense, Erpenbeck $(2006,8)$ defines meta-competences 'as initial dispositions which first substantiate and facilitate the development of basic and derived self-organisation dispositions, namely competences.' So they are competences insofar as they have an impact on actions and unlike the other competences, they have an effect on actions but not immediately and directly. In this respect, it makes sense to understand meta-competences as indirect ones and classic competences as direct ones.

From what has been said, it becomes clear that the first metacompetence has already been presented: it is action competence which is to be understood as a meta-competence because it refers precisely to direct competences, steering and leading them to make the action successful.

TRANSFER COMPETENCE

It may not be unimportant to approach the problem of transfer first from a purely formal perspective. In order to do so, let us look at the pure and formal logic, as it is for instance taught in philosophy and also computer science. One of the best-known final forms is the so-called syllogism, which has the following format:

All S are P.

$\mathrm{R}$ is an $\mathrm{S}$.

Hence: $\mathrm{R}$ is $\mathrm{P}$.

For example, this formal conclusion may take the form:

All humans are mortal.

Socrates is a human.

Hence: Socrates is mortal.

The decisive proposition is not the actual conclusion as one might perhaps assume; this necessarily results from the antecedents. The second sentence is decisive: that is, the classification of Socrates among humans. In other words, the ability to recognise that Socrates is a special case of what is stated in general (that is, a human) is central. Now the connection to transfer becomes clear, because here the 
same problem exists: learners should realise that the concrete problem they are facing (or will be faced with) is interpreted as a special case of a general problem. Although this general problem has been discussed in the training, however, there is often no real practical relevance for the participants: a transfer does not take place.

From this formal clarification of the actual problem we now must come to the central meta-competence: As it should have become clear from the formal perspective, transfer competence in this context is perhaps the most important meta-competence. Transfer describes the action of transferring skills from one situation or context to another situation or context (Schulte 2014, 17). In her own definition, Seidel $(2012,18)$ has a slightly different focus:

The term transfer refers to the changed workplace behaviour of an employee in situations in the workplace that are either characterised by modified or completely new work tasks or in which routine tasks dominate that one [could not handle before but] is able to handle now (meaning: more efficiently) by means of transfer.

Both definitions make it clear that, especially in the context of further education and competence development, the transfer of what has been learned is of crucial importance since the application in the professional context is the decisive factor of any training measure. Against this background, transfer competence - the ability or ability to transfer knowledge that has been learned - can be understood as a way of achieving and implementing the acquired knowledge in the workplace. Transfer has many aspects to be considered. For example, Schulte $(2014,20)$ emphasises that learning plays a central role in this context: 'Successful transfer is a desired, observable behavioural change of individuals in an application context due to learning processes in a learning context, considering subjectively both internal and external (in particular: social and organisational) transfer conditions.'

Consequently, if the concept of transfer is to be considered, a difference must be made between workplace situations and the specific conditions prevailing there and the actual learning situation. Learning usually takes place in a protected atmosphere while in the workplace usually more complex situations are encountered. The atmosphere there, for the most part, is not protected.

This is where the real problem lies: in classic learning processes, specific, clearly defined situations are specified. The key here is complexity reduction: only the essentials come into consideration.

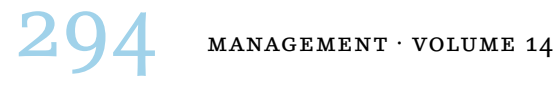


Anything that could distract from this is not brought into focus. It becomes clear that on the one hand the place of learning can by no means be compared with concrete situations in the workplace; on the other hand, what is learned and by which means, that is, the setting of learning, can be described as formal. Both aspects of learning are justified. On the one hand, a specific learning atmosphere must be created if training is to succeed in an efficient and effective way. On the other hand, the formal focus on a problem offers the opportunity to present it without situations that distract from the problem. Nevertheless, these two factors make the transfer difficult.

\section{FAILURE OF TRANSFER}

Perhaps the best approach to transfer competence is to first have a look at why transfer fails. In research, three explanatory models are discussed, all of which are connected with the concept of 'inert knowledge' (Renkl 1996, 78):

- Meta process explanation: Assumes that although the 'right' knowledge is available but the fact that one cannot resort to it, is due to deficient meta-cognitive control processes.

- Structural deficit explanation: There are gaps in knowledge that prevent it from being used.

- Situation explanation: The traditional concept of knowledge and transfer is called into question. The basic assumption is that knowledge is always bound to specific situations.

It can be assumed that all three models explain how inert knowledge arises. In that sense, the different approaches do not compete with each other, but rather complement each other. Against the background of inert knowledge, a further definition of the concept of competence can now be cited: Competences are not just inert knowledge, but rather active or dynamic knowledge; a knowledge that in itself steers an action.

It must be the central task of competence development programmes to prevent the emergence of inert knowledge. Against the background of the above models, this means that knowledge must be sized down in case of doubt, i.e. any existing gaps in knowledge must be found and then filled. Furthermore, the provided knowledge must be as close to reality as possible. The trainee or participant must at least have a rough idea of which concrete situations this knowledge is useful for. Competence development programmes, however, find it difficult to address this first point: meta-cognitive steering processes are very unlikely to be influenced. 


\section{Volition, Transfer Competence and Competence Development}

From what has been said, competence development programmes must work with particular emphasis on preventing the development of inert knowledge. Inert knowledge is prevented by requiring specific knowledge in practice to solve a specific problem.

At this point, however, a problem arises: while the transfer of the acquired skills is relatively easy, since learning is always based on practice within the training, this is much more difficult for competences. Since they are designed for the ability to act, but no abstract learned situation is identical with those encountered in business reality, it quickly becomes clear that competences are much more difficult to develop. Inert knowledge can quickly establish itself.

\section{VOLITION AS A META-COMPETENCE}

Before discussing the actual concept of activation of transfer competence, a further meta-competence, which is of central importance in the context of interest here, must first be addressed: volition. To begin with, volition can be understood as the conscious and intentional implementation of goals or the motivation to achieve results. Pelz understands it as will power but also self-regulation and ultimately even implementation competence (Pelz 2017, 106). Although volition is a necessary condition for a successful implementation, it is not the sufficient condition. But precisely because it is a necessary condition (and certainly the most important one), it needs to be briefly discussed here. Pelz defines volition more as an ability to control motives, thoughts, feelings, impulses, and actions so that people achieve their goals in an efficient manner (Pelz 2017, 106). Accordingly, volition can be understood as the relationship between volitional effort and the result of that effort (Pelz 2017, 106). It becomes clear that implementation in this context is by no means just transfer. Rather, implementation means that, based on a goal, a plan is designed that leads to actions that turn into results. Volition is crucial here because it controls feelings, thoughts, knowledge and ultimately actions.

Therefore, it is not transfer competence that is related to implementation competence but rather action competence. If action is understood as the achievement of goals or purposes by using certain means, then it becomes clear that action competence and implementation competence have a large overlap. One should, however, be aware of differences between these two competences. Action com-

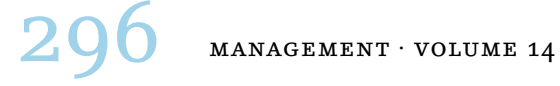


petence, as presented above, was the set of professional, methodical, social and self-competence. One could say that here the view on humans is made from the 'outside' so-to-speak. Implementation competence, on the other hand, insofar as it is related to volition, is more of a look from the 'inside.'

Acting competently cannot be attributed only to external causes. Just because someone has professional, methodological, social and self-competence, this does not mean they act competently. The actual competent act is to make a purposeful action. At the same time, however: volition alone is not enough for successful actions. From the perspective of action competence, volition is always already presupposed and therefore not specifically addressed. From the perspective of volition, on the other hand, the ability to act is always required, which does not have to be specifically addressed here either. But here too, having a large volition alone, but not having the above-mentioned ability to act is not enough for successful actions.

This difference makes it clear why Pelz comes to speak of completely different competences in his observations. These are (Pelz 2017, 106):

- Steering one's attention and focusing on the essentials

- Emotional and self-management

- Self-confidence and assertiveness

- Predictive planning and creative problem solving

- Goal-oriented self-discipline due to a deeper meaning of the task to

These competences differ significantly from those that constitute action competence. While the latter is more akin to action in a narrower sense, these competences revolve around focusing on a problem.

It becomes clear that volition does not only mean intensity of will but goes beyond that. In a sense, it represents the link between personal will and the real world; it means the ability of the person to influence the world according to his/her wishes. Therefore, it is also to be distinguished from motivation which merely indicates the reason for an action or the willingness to act but in no way looks to the success of the action.

With the term volition also the success of an action comes into focus. It could be said that people with a high degree of volition are more successful in overcoming problems than others because they have a higher degree of efficiency than those (resulting from the relationship between the will used and the degree of achievement 
of the goal). At the same time, this is not yet transfer competence, because this means that something learned is successfully implemented in everyday business. This in turn means (in the context of competence development) that the person now has specific competences that he/she did not have before and now applies in everyday life.

The term volition, on the other hand, assumes that a person possesses it right from the start. Pelz rightly says that the concept of motivation alone cannot explain why it is above all the cEos of mediumsized global market leaders who cannot explain why they are capable of using modest resources successfully in an often adverse environment without external motivation despite many defeats and setbacks. He quite rightly points out that these individuals often have a strong capacity for self-control and self-regulation. However, this is not transfer competence.

It also becomes clear from what has been said why volition is a meta-competence. Because it does not affect actions directly it rather can be regarded as the reason why and in what context specific actions are carried out.

However, how these actions are performed has no meaning in this context. When translating a goal into a result, different competences are used (such as attentional control, self-confidence or assertiveness, problem-solving skills etc.) that are controlled by volition.

\section{VOLITION AND TRANSFER}

Volition is therefore the central competence in the implementation of a plan. In this sense, on the one hand, it is a condition of the possibility for transfer. Because a successful transfer in the context of a competence development measure cannot be carried out without will power. On the other hand, it is also necessary if the newly acquired competence is used in the implementation of a plan.

Volition, however, does not have any influence on transfer itself. Rather, Pelz assumes that competences are available but that these actions must be implemented in such a way that they are 'consistent.' Therefore, the focus of Pelz's considerations is not transfer but rather successful actions, which is reflected in the achievement of the goal.

\section{A CLOSER LOOK AT TRANSFER COMPETENCE}

The short presentation of transfer competence given above can and must now be supplemented and thus clarified. Transfer is, as stated above, the transfer of knowledge and skills from one situation or

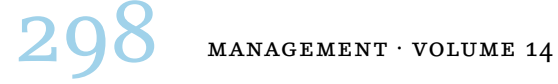


context to another situation or context. Especially in the context of education and training in general, this competence is very important. One of the most important works in this field is Transferkompetenz und Transfer: Theoretische und empirische Untersuchung zu den Wirksamkeitsbedingungen betrieblicher Weiterbildung [Transfer Competence and Transfer: Theoretical and Empirical Study on the Conditions of Effectiveness of Corporate Training] by Seidel (2012). In her model of competence development, which she presents in this work, she puts transfer competence at the centre. It is based on the assumption that the transfer success of a training is significantly influenced by the individual transfer competence. This depends on situational and personal factors of influence, in addition to procedural and declarative expertise, intrinsic and extrinsic transfer motivation and self-control (the latter factors make it easy to recognise volition as described by Pelz 2017). The transfer itself as well as the results have a feedback effect on transfer competence.

It is important that it is foremost personal qualities such as cognition, motivation etc. that have an impact on a successful transfer performance. Organisations, however, have less influence on transfer performance. It follows that transfer competence itself cannot be developed because personal qualities, above all cognitive ability but ultimately also volition, can only be increased within a very limited framework. Successful competence development therefore requires transfer competence. But if this cannot be developed, and it is further assumed that not all people have a comparable potential in terms of transfer competence, then this means that not everyone is suitable for a competence development programme. Furthermore, this means for competence development programmes that they can only activate transfer competence. Metaphorically, one could say that it was 'asleep' or 'buried' before participating in the programme. It follows that, since not everyone has this competence, not everyone is suited for a competence development programme, and therefore employees that one wants to develop further must be selected before the actual programme starts.

FROM THEORY TO PRACTICE I: PROBLEMS WITH TRADITIONAL TRAININGS

It has been known for some time that the usual training and support measures for managers and prospective executives do not always achieve the desired results. Many such trainings do not only fail to recognise that the participants have different gaps within their range of competences but moreover that transfer competence is not or only 
partially activated. The consequence is that individual competence development is neither goal-oriented nor does it have a lasting effect.

In this respect it is justified to ask whether the classical approaches, which also include follow-up or impulse days, webinars, chats etc. result in a high transfer into daily business routine. It has to be stressed though that just concentrating on modern media, like the Internet with all its possibilities, does not guarantee transfer success. Furthermore, it should be noted here that for this type of training push orientation is characteristic: participants get a large amount of information, of which, however, only a relatively small amount is useful for the them. This form of training is quite problematic. It resembles a common type of teaching in didactics: Frontalunterricht (teacher-centred teaching). Even though Frontalunterricht could be better than its reputation, it should not be concealed that there are also a number of problems linked to it. For example, a homogeneous learning group is a pre-condition (Merkens 2010, 56). It should be noted here, however, that the problem faced by teachers in schools also arises in adult education: the homogeneity of learners is by no means the norm. Rather, it can be assumed that in each traditional training course the trainees are structured in a heterogeneous way: this applies both with regard to age, experience but also with regard to the position that the respective person occupies or is supposed to occupy in his/her company. Even school teachers often have their problems in offering a good quality teacher-centred teaching which is why this type of teaching might also be problematic in the further education sector.

On the side of the trainers and their institutes, it can be stated that they can confirm the (apparent) success of the training by measuring the participants' satisfaction, but a look at everyday business life does not take place. Whether an actual transfer success can be observed is usually not considered.

FROM THEORY TO PRACTICE 2: A SUCCESSFUL COMPETENCE DEVELOPMENT PROGRAMME

Against the background of obvious problems, which have just been briefly presented, one of the authors of these lines and a colleague of his' has had considerable doubts about the effectiveness of traditional training measures a few years ago. They decided to develop a competence development programme that does not only contain push elements but also pull elements (Bach and Kring 2015). As a result, training is done together with the person to be developed and 


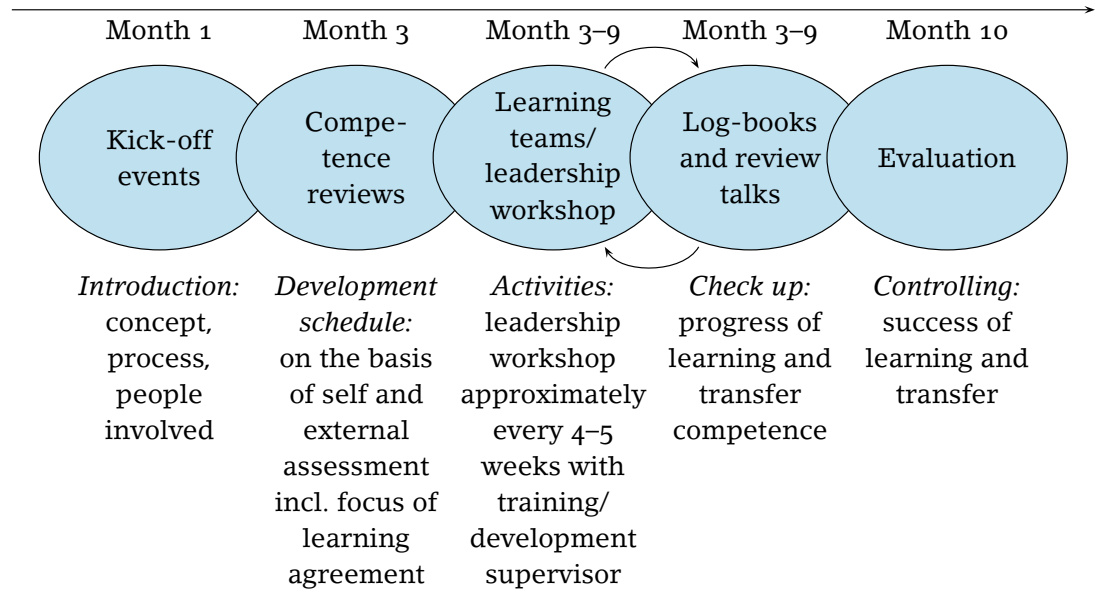

FIGURE 1 Programme Elements of the Praxistransfer System (adapted from Bach and Kring 2015, 6)

in a demand-oriented way, that is, in his/her essential fields of optimisation.

In addition to a few other questions that this new programme had to answer positively, the focus was on the question of transfer into everyday business. This lead to some features that the new competence development programme had to fulfil: the transfer of what one has learned into everyday business has to be significantly increased compared to conventional trainings. Furthermore, the programme focuses on individual development in key competences.

The result of these considerations and targets is the programme Praxistransfer (transfer into practice) which consists of five elements:

- Kick-off event

- Competence reviews

- Learning teams/Leadership workshop

- Log-books and review talks

- Evaluation

Figure 1 illustrates the actual process.

Finally, the central elements that activate transfer competence are presented in the following.

The second step after the introduction and kick-off is a competence review: in the review an assessment of the individuals' needs and development planning are in focus. It is important in this context that not only a participant's self-assessment is focused on but 
also their supervisor's assessment comes up for discussion. The aim of this conversation is to elaborate people's learning and development goals. It must be emphasised here that this is not about acquiring knowledge. It is about building a set of behavioural competences. This results in an agreement of learning priorities.

The actual centrepiece of the programme is the leadership workshop. The participants work in learning teams on their key competences (four to five participants all of whom are on the same level and who are not colleagues). Working on competences is organised in a self-responsible way by the participants even though the management workshop is hosted by a trainer. After the leadership workshop, the participants go back to their companies and try to implement what they have learned in everyday life. In a subsequent meeting, experiences are shared and critically reflected in the group.

Lastly and in addition to the leadership workshop the log-book must be mentioned. Participants are invited to submit their experiences in writing. The participants should try to get to know themselves better in terms of their weaknesses and thus analyse their needs regarding competence development, but also assess their progress and improvement. This point essentially serves to review one's own progress in learning and, at the same time, to find out in which areas no progress has been made. With these results in mind, the participants meet again and work on these weaknesses autonomously.

In conclusion, Praxistransfera has actually proven to be able to develop various competences. Among many other reasons the main reason for this may well be the process of activating transfer competence and avoiding inert knowledge. Above all, the leadership workshop plays a decisive role in this: the fact that the participants report on their experiences and give each other tips, which in turn stem from their experience, prevents them from drifting off into a purely theoretical discussion. The practical relevance of what has been taught becomes obvious. By this, the formation of inert knowledge is prevented. Likewise, the explicit request for transfer, which prevents the formation of inert knowledge, should at the same time activate transfer competence. Transfer competence and the prevention of inert knowledge ultimately are two sides of the same coin.

\section{Conclusion}

The programme presented here is noticeably different from classic training programmes. The activation of transfer competence should primarily be effected by focusing on the specific person with his/her 
strengths and weaknesses, but above all the review talks, in which the successes and failures are discussed and an attempt is made to find out the reasons - especially for the failures, are likely to account for the largest share of this activation. By uncovering the reasons, the participant is immediately shown why he/she has failed and can therefore later adapt his/her behaviour. Overall, the concrete procedure therefore resembles a cybernetic cycle: the individual measures are continued until the competence development has aligned itself with the given success indicators. Even if this cycle is the core of the programme, yet another feature distinguishing this programme from classic programmes should not be concealed: the teacher or trainer is not the actual person who communicates knowledge to the learners by means of Frontalunterricht (teacher-centred learning). Rather, the learners teach themselves.

The function of the learning tutor is seemingly simple: he/she gives inputs, facilitates and sets the framework - the actual learning content is largely conveyed by the participants themselves. This has many advantages: because the learners learn from themselves, a connection to their daily business life is made. It immediately becomes clear to them that the matters discussed in the workshop are not theoretical, which has little or no significance in everyday life, but rather, precisely because of this, the significance of what has been learned becomes clear to everyone. Furthermore, in this way the concrete problems of each individual are discussed and the participants search for possible solutions together. Not only does this address the problems of each person, but above that everyone is involved in solving the problems of others.

If it is assumed that the problems of others could be one's own problems of tomorrow, then this strategy can also be seen as preventive. However, and above all, even if this is not true, each participant will be provided with problem-solving strategies by actively helping to solve other peoples' problems. In this sense, the participants do not only learn to improve their competences, but also how to improve them independently.

Finally, this is a list of the three success factors of the aforementioned competence development programme:

- There is a focus on the individual.

- Transfer competence is activated by means of a cycle process.

- The members of the learning team learn from each other and not from a teacher or trainer. The tutor is in the background most of the time and intervenes only when absolutely necessary. 


\section{References}

Bach, C., and W. Kring. 2015. 'Praxistransfer: Innovative Methodik zur nachhaltigen Steigerung der Transferleistung. Methodik, Wirksamkeit, Praxis.' PersonalEntwickeln 200:1-20.

Burgoyne, J. 1988. Competency Based Approaches to Management Development. Lancaster: Centre for the Study of Management Learning.

Erpenbeck, J. 2006. 'Metakompetenzen und Selbstorganisation.' In $\mathrm{Me-}$ takompetenzen und Kompetenzentwicklung, edited by J. Erpenbeck, 5-14. Berlin: esm Satz und Grafik GmbH.

Erpenbeck, J., and J. Sauer. 2001. 'Das Forschungs- und Entwicklungsprogramm »Lernkultur Kompetenzentwicklung «.' In Arbeitsgemeinschaft Qualifikationsentwicklungs-Management, 289-335. Münster: Waxmann.

Heyse, V., J. Erpenbeck, and S. Ortmann. 2015. 'Einleitung: Ein Meer von Kompetenzen.' In Kompetenz ist viel mehr: Erfassung und Entwicklung von fachlichen und überfachlichen Kompetenzen in der Praxis, edited by V. Heyse, J. Erpenbeck, and S. Ortmann, 13-18. Münster: Waxmann.

Merkens, H. 2010. Unterricht: Eine Einführung. Wiesbaden: vs Verlag für Sozialwissenschaften.

Pelz, W. 2017. 'Umsetzungskompetenz als Schlüsselkompetenz für Führungspersönlich-keiten: Eine theoretische und empirische Analyse.' In Führung im Zeitalter von Veränderung und Diversity: Innovation, Change, Merger, Vielfalt und Trennung, edited by C. von Au, 103-24. Wiesbaden: Springer Fachmedien.

Renkl, A. 1996: 'Träges Wissen: Wenn Erlerntes nicht genutzt wird.' Psychologische Rundschau 47:78-92.

Schäfer, E. 2006. Betriebliche Kompetenzentwicklung. Wiesbaden: vs Verlag für Sozial-wissenschaften.

Schulte, F. P. 2014. Die Bedeutung und Erfassung des Erwerbs von TheoriePraxis/Praxis-Theorie-Transferkompetenz im Rahmen eines dualen Studiums. Essen: Beitrag dem ғом Hochschule für Oekonomie \& Management.

Seidel, J. 2012. Transferkompetenz und Transfer: Theoretische und empirische Unter-suchung zu den Wirksamkeitsbedingungen betrieblicher Weiterbildung. Landau: Verlag Empirische Pädagogik.

This paper is published under the terms of the Attribution-

NonCommercial-NoDerivatives 4.0 International (CC BY-NC-ND 4.0)

License (http://creativecommons.org/licenses/by-nc-nd/4.o/). 